\title{
Kinetic analysis of the hydrocarbon total oxidation using individual measured adsorption isotherms
}

\author{
Gregor Kiedorf $^{1^{*}}$, Tanya Wolff ${ }^{1}$, Andreas Seidel-Morgenstern ${ }^{1,2}$, Christof Hamel $^{2,3}$ \\ ${ }^{1}$ Max Planck Institute for Dynamics of Complex Technical Systems, Sandtorstr. 1, D-39106 Magdeburg, Germany \\ ${ }^{2}$ Otto von Guericke University, Institute of Process Engineering, Universitätsplatz, 2, D-39106 Magdeburg, Germany \\ ${ }^{3}$ Anhalt University of Applied Sciences, Applied Biosciences and Process Engineering, Bernburger Str. 55, D-06366 Köthen, Germany
}

\begin{abstract}
The partial and total oxidation of $\mathrm{C}_{2} \mathrm{H}_{4}, \mathrm{C}_{3} \mathrm{H}_{6}$ separately and in mixtures and $\mathrm{CO}$ on a $\mathrm{CrO}_{\mathrm{x}} / \gamma$ $\mathrm{Al}_{2} \mathrm{O}_{3}$ catalyst was studied to describe the reaction kinetics. Based on catalytic cycles mechanistic kinetic models of all reactions were derived. For reduction of adjustable parameters individually measured adsorption isotherms were used to parameterize adsorption constants in the kinetic models. The complex reaction network was decomposed in 3 sub-networks to support parameter estimation, to quantify and validate kinetic rate approaches. The best fit for hydrocarbon reactions was achieved by an Eley-Rideal and CO by a Mars-van Krevelen approach.
\end{abstract}

Keywords: alkenes, catalytic oxidation, network analysis and kinetics, parameter estimation, model reduction

* Corresponding author: phone: +49-391-6110-449, fax: +49-391-6110-403, e-mail: kiedorf@mpi-magdeburg.mpg.de 


\section{Introduction}

The exhaust emission standard for industrial facilities, coal-fired power stations and automobiles was rapidly increased in the last decades. Therefore, much research has been dedicated to identify suitable catalysts for the total oxidation of model volatile organic compounds (VOC) [13]. In this connection, noble metal catalysts proved to be most active for such reactions [4, 5]. Frequently used active metals are platinum [5-9], rhodium [8] and palladium [10, 11] supported on $\gamma-\mathrm{Al}_{2} \mathrm{O}_{3}$ particles or monoliths. In addition, combinations of these metals are favorite $[12,13]$. However, based on lower costs, higher stability and more unsusceptible against catalyst poisoning the trend tends to the application of transition metal oxide catalysts $[1,2,14,15]$. Therefore, the most active oxidation catalyst combination is $\mathrm{CrO}_{3}$ [1]. Also vanadium based catalysts [16-18] offer high activity and are used, too. However, the oxidation suitability depends also from the type of the reactants. Hence, variable catalyst activity can occur [19, 20].

Based on the kind of the catalyst different reaction mechanisms are preferred. Using noble metal catalysts an adsorption-desorption mechanism is often proposed. In this case, all reactants have to adsorb at an active catalyst site. Afterwards, these adsorption sites will react with each other and the products desorb immediately. That can be quantified using the well-established Langmuir-Hinshelwood-Hougen-Watson approach. Simplifications are possible if only one reactant adsorbs at the catalyst surface and others react from the gas phase with the adsorbed species (Eley-Rideal mechanism). Transition metal oxide catalysts works as oxygen storage. The total oxidation consumes lattice, adsorbed and gas phase oxygen, respectively [3, 15, 20]. Consequently, an oxidation-reduction cycle can be determined [21, 22]. However, in many cases the real reaction mechanism remains unknown, in spite of sophisticated ex and in situ spectroscopy techniques [23]. In literature different mechanisms of the total oxidation of shortchain olefins and carbon monoxide on a $\mathrm{CrO}_{\mathrm{x}}$ catalyst were discussed [20, 22]. Yao [20] prepared and analyzed $\alpha-\mathrm{Cr}_{2} \mathrm{O}_{3}$ with different morphological appearances for the total oxidation of short-chain olefins, alkanes and carbon monoxide. In accordance to the adsorption measurements it was concluded that the investigated $\mathrm{Cr}_{2} \mathrm{O}_{3} / \mathrm{Si}$ catalyst offer no surface lattice oxygen for the total oxidation reaction mechanism. In contrast Murzin and Salmi [22] illustrated that $\mathrm{Cr}_{2} \mathrm{O}_{3}$ follows the $\mathrm{MvK}$ mechanism for the carbon monoxide oxidation.

Based on these mechanisms different global kinetic rate approaches can be determined [22, 24, 25]. However, at special conditions experimental measured concentration profiles can be 
explained with several rate models $[26,27]$. The rate models used for the kinetic modeling are presented in section 3 .

These global kinetic rate approaches possess a high number of free parameters. The adsorption constants in the kinetic expressions are typically estimated by kinetic measurements [28-30]. The simultaneous estimation of the temperature dependence of reaction and adsorption is difficult because of ill-conditioned inverse problems in optimization algorithm [31, 32]. In literature $[33,34]$ the mathematical model reduction technique, the subset selection method was introduced. It allows the identification of ill-conditioned parameter subsets in order to exclude the parameters from the estimation task. As a result, a reduced model with estimable parameters can be suggested. This method was successfully demonstrated for different problems [25, 3537]. The mathematical description of the global formulation of the subset selection can be reviewed in $[25,36]$. For a more detailed time or space-resolved parameter analysis a local subset selection is suitable [37].

For the reduction of adsorption reaction mechanism model based on additional individual measured adsorption isotherms is obviously. In [32, 38, 39] independent adsorption measurements were performed for reactants and products in the homogeneous or heterogeneous catalyzed acetic acid esterification and subsequently the obtained parameters are integrated in the reaction kinetic approach. Thus, the physical meaning of the adsorbed constants can be increased while the estimated $95 \%$ confidence intervals of the kinetic parameters are decreasing. Also the adsorption behavior of reactants and products on zeolite catalysts was intensively studied. Based on the adsorption equilibrium different reactant concentration on the catalyst surface can occur [31]. For that reason, Denayer and Baron [40] investigated several chain lengths and branched paraffins, as possible reactants, for the adsorption behavior in a broad temperature range. Corma et al. [41] and Al-Sabawi et al. [42] determined adsorption parameters and heat of adsorption of long chain hydrocarbons for zeolite supported catalysts in the range from 400 to $500{ }^{\circ} \mathrm{C}$ and 450 to $550{ }^{\circ} \mathrm{C}$, respectively.

However, in many cases the adsorption measurements of reactants at a highly active catalyst are very difficult, because of possible cracking reactions at the desired temperature range. Therefore, adsorption measurements were often carried out at room temperature [42-44]. Thus, the independent estimated adsorption parameters have to be extrapolated for the reaction kinetic analysis. Additionally a catalyst species transformation based on the different temperatures can 
occur. Hence, the adsorption measurements cannot reflect the adsorption behavior at reaction conditions [42].

The required adsorption isotherms of the reactants and products are given by previous work [45]. In this preliminary work adsorption isotherms were measured in a broad temperature and concentration range using the frontal analysis method [46]. Following competitive adsorption isotherms of the reactants were predicted by means of the ideal adsorbed solution theory [47, 48] and the Multi-Langmuir model, respectively. In the range of higher concentration the studied models reflects the experimental data well. Based on this reason the ordinary Multi-Langmuir model is used in the kinetic modeling.

The structure of the present work is characterized as follows: At first global kinetic rate approaches for the oxidation reactions of ethylene, propylene and carbon monoxide will be derived for three different reaction mechanisms in the postulated catalytic cycles. Furthermore, the reactor model including the component and impulse balance equation as well as the kinetic parameter estimation will be introduced. In addition, the kinetic measurements are shown with subsequent validation of each sub-network and concluding the total reaction network.

\section{Catalyst characterization and reaction network}

The chrome-alumina catalyst used in the experiments was prepared at the Max Planck Institute in Magdeburg. The exact procedure is already presented by Kiedorf et al. [45]. The chemical analysis of the fresh prepared catalyst was carried out by Inductively Coupled Plasma Optical Emission Spectroscopy (ICP-OES) using iCAP 6500 Duo (Thermo Fisher) system. The catalyst contained $1.0 w t .-\%$ chrome and $38.4 w t .-\%$ alumina. Nitrogen physisorption isotherms were measured at $-196{ }^{\circ} \mathrm{C}$ using a Nova 2000e (Quantachrome) analyzer. The sample was degassed for $24 \mathrm{~h}$ at $120{ }^{\circ} \mathrm{C}$ in vacuum. The specific surface area was estimated by BET and the pore diameter calculated by $\mathrm{BJH}$ method. The $\mathrm{CrO}_{\mathrm{x}} / \gamma-\mathrm{Al}_{2} \mathrm{O}_{3}$ catalyst revealed a surface area of $152.7 \mathrm{~m}^{2} / \mathrm{g}$ and a pore diameter of $8.7 \mathrm{~nm}$ according to the $\gamma-\mathrm{Al}_{2} \mathrm{O}_{3}$ support $\left(157.7 \mathrm{~m}^{2} / \mathrm{g}\right.$ and $8.0 \mathrm{~nm}$ ). TPR profiles were obtained on a BEL-CAT Catalyst Analyzer (BEL Japan Inc.) using $10 \%$ hydrogen in argon. Only one broad reduction peak is apparent below $400{ }^{\circ} \mathrm{C}$ for the $\mathrm{CrO}_{\mathrm{x}} / \gamma-\mathrm{Al}_{2} \mathrm{O}_{3}$ catalyst. It appears that this corresponds to $\mathrm{CrO}_{3}$. Accordingly, above $400{ }^{\circ} \mathrm{C}$ $\mathrm{Cr}_{2} \mathrm{O}_{3}$ adsorption sites are present. Based on these measurements, the two oxidation states of chromium, $\mathrm{Cr}^{6+}$ and $\mathrm{Cr}^{3+}$, can be observed. Sattler et al. [49] investigated Raman and UV-Vis 
spectra of a $\mathrm{CrO}_{\mathrm{x}} / \mathrm{Al}_{2} \mathrm{O}_{3}$ catalyst. Therefore, the additional $\mathrm{Cr}^{2+}$ and $\mathrm{Cr}^{5+}$ species were identified as active components in dehydrogenation reaction. Further the structure of the several present chrome centers is analyzed. $\mathrm{Cr}^{3+}$ is found as an isolated center stabilized by the catalyst support and in amorphous clusters. In this connection it is pointed out that these clusters are invisible in the available XRD analysis (X'Pert Pro diffractometer by PANalytik). Crystalline structures are observed only at higher chromium loading. Accordingly, based on this analysis the additional observed chrome species can be expected on the presented catalyst. A more detailed analysis of the presented catalyst will be forwent in this work. Rather the reaction kinetic analysis of the total oxidation of ethylene, propylene and carbon monoxide is the scope of this manuscript.

The postulated total oxidation reaction network is presented in fig. 1. The reaction network consider the total $\left(r_{1}, r_{3}\right)$ and partial $\left(r_{2}, r_{4}\right)$ oxidation reactions of the reactants ethylene and propylene, respectively [50]. Furthermore, the product of the partial oxidation reaction, carbon monoxide, can completely be oxidized $\left(r_{5}\right)$ [28]. The thermal cracking reaction from propylene to ethylene $[51,52]$ were only observed in a range below $0.1 \%$. For that reason, this reaction was not quantified in this contribution.

According to $\mathrm{Hu}$ et al. [53] and Kiedorf et al. [25] the experimental and model study of the complex total reaction network was subdivided in three sub-networks. Starting investigations with the smallest and independent sub-network the carbon monoxide oxidation $\left(r_{1}-r_{4}=0\right)$ the complexity was increased and finalized at the complete network $\left(r_{1}-r_{5} \neq 0\right)$. The intermediate steps include the ethylene sub-network $\left(r_{3}-r_{4}=0\right)$ and the propylene sub-network $\left(r_{1}-r_{2}=0\right)$. For this approach, the experimental measurements were adapted at each sub-network. Finally, the transfer of the already estimated kinetic parameters at the sub-networks was reviewed at the complete network.

\begin{tabular}{llc}
\hline \multicolumn{1}{l}{ Sub-network } & Name & $\begin{array}{c}\text { Abbreviations of } \\
\text { involved reaction rates }\end{array}$ \\
- I & Oxidation of $\mathrm{CO}$ & $\boldsymbol{r}_{\mathbf{5}}$ \\
- II & Oxidation of $\mathrm{C}_{2} \mathrm{H}_{4}$ & $\boldsymbol{r}_{\mathbf{1}}, \boldsymbol{r}_{2}, r_{5}$ \\
- III & Oxidation of $\mathrm{C}_{3} \mathrm{H}_{6}$ & $\boldsymbol{r}_{3}, \boldsymbol{r}_{\mathbf{4}}, r_{5}$ \\
- Total reaction network & Oxidation of $\mathrm{C}_{2} \mathrm{H}_{4}$ and $\mathrm{C}_{3} \mathrm{H}_{6}$ & $r_{1}, r_{2}, r_{3}, r_{4}, r_{5}$ \\
\hline
\end{tabular}




\section{Catalytic cycle and mechanistic models}

The reaction kinetic analysis and modeling of the partial and total oxidation of ethylene, propylene and carbon monoxide was performed using the Mars-van Krevelen (MvK), EleyRideal (ER) and the Langmuir-Hinshelwood (LH) mechanism. The derivation of the rate models was performed using the catalytic cycles (see fig. 2) and the Christiansen methodology [22, 24, 25]. Basic requirement of this method is the pseudo-first order rate assumption of all elementary reaction steps in the catalytic cycle considered. In addition no step involves more than one intermediate active catalyst species.

According to the MvK reaction mechanism (fig 2a), in the first step the reactant oxidation proceeds with lattice oxygen on the solid catalyst surface. The reduced catalyst will be reoxidized by gas phase oxygen (second step). If a reversible catalytic cycle is considered (see fig. 2a) the general two step reaction formula is given in eq. 1 .

$$
r_{1-5}^{\mathrm{MvK}}=\frac{\omega_{\mathrm{red}}^{+} \omega_{\mathrm{ox}}^{+}-\omega_{\mathrm{red}}^{-} \omega_{\mathrm{ox}}^{-}}{\left(\omega_{\mathrm{red}}^{+}+\omega_{\mathrm{ox}}^{+}+\omega_{\mathrm{red}}^{-}+\omega_{\mathrm{ox}}^{-}\right)}
$$

Insertion of the several steps working from the assumption of an irreversible catalytic cycle the eq. 1 yields to the general MvK reaction kinetic equation (eq. 2).

$$
r_{1-5}^{\mathrm{MvK}}=\frac{k_{\mathrm{red}}^{+}(T) p_{\mathrm{C}_{3} \mathrm{H}_{6} / \mathrm{C}_{2} \mathrm{H}_{4} / \mathrm{CO}} k_{\mathrm{ox}}^{+}(T) p_{\mathrm{O}_{2}}}{\left(k_{\mathrm{red}}^{+}(T) p_{\mathrm{C}_{3} \mathrm{H}_{6} / \mathrm{C}_{2} \mathrm{H}_{4} / \mathrm{CO}}+k_{\mathrm{ox}}^{+}(T) p_{\mathrm{O}_{2}}\right)}
$$

The derivation of the corresponding overall kinetic equation for the ER mechanism shown in fig. $2 \mathrm{~b}$ can be performed in an analogues manner leading to eq. 3 . For the presented catalytic cycle oxygen adsorbs at the active catalyst species first $\left(\omega_{1}\right)$. Afterwards the hydrocarbon or carbon monoxide (not shown in fig. $2 b$ ) reacts with the adsorbed oxygen from the gas phase $\left(\omega_{2}\right)$. The reaction products water and carbon dioxide can adsorb at the catalyst surface and limit the free adsorption sites, too. The transfer of this mechanism to the total oxidation of short-chain olefins with dissociated oxygen results in a three step catalytic cycle ( $\omega_{1}^{\prime}$ is also considered).

$$
r_{1-5}^{\mathrm{ER}}=\frac{k_{1-5}^{\mathrm{ER}}(T)(K p)_{\mathrm{O}_{2}}^{0.5} p_{\mathrm{C}_{3} \mathrm{H}_{6} / \mathrm{C}_{2} \mathrm{H}_{4} / \mathrm{CO}}}{\left(1+(K p)_{\mathrm{O}_{2}}^{0.5}+(K p)_{\mathrm{CO}}+(K p)_{\mathrm{CO}_{2}}+(K p)_{\mathrm{H}_{2} \mathrm{O}}\right)}
$$

The Christiansen methodology is not able to handle catalytic cycles with more than one catalyst species involved. Thus, the derivation of the Langmuir-Hinshelwood-Hougen-Watson model failed. Such reaction approach has to determine by means of the classical way [22, 24, 54]. 
Therefore, the surface reactions of the adsorbed reactants were assumed as rate determining step. Heynderickx et al. [3] discussed also the adsorption steps of the reactants as rate determining step. If there is no steady state adsorption condition of the reactants available adsorption kinetics can be included in the phase balance equation. Corresponding to the assumption of an oxygen dissociation $[3,55]$ at the catalyst surface the final reaction rate can be written in general for different reactants as follows.

$$
r_{1-5}^{\mathrm{LH}}=\frac{k_{1-5}^{\mathrm{LH}}(T)(K p)_{\mathrm{O}_{2}}^{0.5}(K p)_{\mathrm{C}_{3} \mathrm{H}_{6} / \mathrm{C}_{2} \mathrm{H}_{4} / \mathrm{CO}}}{\left(1+(K p)_{\mathrm{O}_{2}}^{0.5}+(K p)_{\mathrm{C}_{3} \mathrm{H}_{6}}+(K p)_{\mathrm{C}_{2} \mathrm{H}_{4}}+(K p)_{\mathrm{CO}}+(K p)_{\mathrm{CO}_{2}}+(K p)_{\mathrm{H}_{2} \mathrm{O}}\right)^{2}}
$$

The temperature dependency of the kinetic constants is presented using a typical Arrhenius approach (see eq. 5).

$$
k_{j_{\mathrm{R}}}(T)=k_{\infty, j_{\mathrm{R}}} \exp \left(\frac{-E_{\mathrm{A}, j_{\mathrm{R}}}}{R^{\circ} \sigma T}\right)
$$

\section{Reactor model and parameter estimation procedure}

The complexity of tubular reactor models in heterogeneous catalysis differs much from physics involved. Based on computational and parameterization effort a model graduation is suitable. Therefore, Froment and Bischoff [56] classified continuum models of the implemented phases and dimensions. Furthermore, in heterogeneous catalysis models will be distinguished between pseudo-homogeneous phase and heterogeneous phases consideration [54, 57].

The material balance was performed considering a pseudo-homogeneous ideal plug flow tubular reactor (PFTR) model neglecting external and internal mass transport limitations, as well as radial gradients corresponding to the experimental equipment used. Thus, the non-steady state molar flux $\dot{n}_{j \mathrm{c}}$ balance of each component in the fluid phase (eq. 6) contains an axial convection and the reaction term.

$$
\frac{d \delta_{j_{\mathrm{c}}}}{d z}=\frac{m_{\mathrm{cat}}}{L_{\mathrm{seg}}} \sum_{j_{\mathrm{R}}=1}^{N_{\mathrm{R}}} v_{j_{\mathrm{R}} j_{\mathrm{c}}} r_{j_{\mathrm{R}}}
$$

If exclusively non transient behavior will be considered in kinetic modeling the time dependent accumulation can be neglected. The boundary condition is defined by:

$$
\aleph_{J_{\mathrm{c}}}(z=0)=\aleph_{J_{\mathrm{c}}}
$$


Based on difficulties in parameter estimation respective correlations the energy balance will not solved [24]. Rather the temperature profile across the catalyst bed will be approximated mathematically using a polynomial equation of second degree (see appendix). This equation is fitted on values from three thermal sensing elements which are placed across the catalyst bed.

The pressure drop and the gas phase velocity $u_{\text {gas }}$ across the catalyst bed were correlated using the semi-empirical Ergun-equation (eq. 8) which includes the void fraction $\varepsilon$, the dynamic viscosity $\eta_{\text {tot }}$, the catalyst particle diameter $d_{\mathrm{P}}$ and the total gas density $\rho_{\text {tot }}$.

$$
\frac{d p_{\text {tot }}}{d z}=-150 \frac{(1-\varepsilon)^{2}}{\varepsilon^{3}} \frac{\eta_{\mathrm{tot}}}{d_{\mathrm{P}}^{2}} u_{\mathrm{gas}}-1.75 \frac{(1-\varepsilon)}{\varepsilon^{3}} \frac{\rho_{\mathrm{tot}}}{d_{\mathrm{P}}} u_{\mathrm{gas}}^{2}
$$

More detailed information for the Ergun-equation can be found in [58-60].

Based on the individual adjustable volume-surface-ratio of a reactor pipe the heat transfer through the reactor shell is easily managed. Thus, various thermal operation modes are useable. As aforementioned kinetic experiments should be performed isothermal to avoid superposed heat transport phenomena [24].

The kinetic parameter estimation problem was solved using a trust-region-reflective algorithm, which is implemented in the optimization solver 1sqnonlin of MATLAB 8.6.0 (R2015b). The estimation procedure was carried out in two steps [29]. First, initial values were generated at an isothermal regression at each of the experimental investigated temperatures (see $k_{j \mathrm{R}}(T)$ in eq. 5). The second step includes a non-isothermal regression (see $k_{\infty, j \mathrm{R}}$ and $E_{\mathrm{A}, j \mathrm{R}}$ in eq. 5) based on the initial values of the first regression. The used objective function $O F$ follows the sum of least squares method (eq. 9). The resultant $95 \%$ confidence intervals of all estimated parameters were calculated according to Joshi [61].

$$
O F\left(\Theta_{\text {opt }}\right)=\sum_{j_{\text {obs }}=1}^{N_{\text {obs }}}\left(y_{j_{\text {obs }}}^{\text {exp }}\left(y^{\text {in }}\right)-y_{j_{\text {obs }}}^{\text {mod }}\left(y^{\text {in }}, \Theta_{\text {opt }}\right)\right)^{2}
$$

However, also in combination of these two regressions strong parameter correlations may occur. Based on this reason a transformation introduced by Schwaab and Pinto [62] is used that allows estimating the activation energy and the frequency independently. In this approach, a reference temperature is used to estimate on the one hand the ratio of the activation energy, universal gas constant and the reference temperature and on the other hand the sum of the first parameter and the logarithm of the frequency factor. Subsequently, with the final formulation the reference temperature can be excluded so that the general Arrhenius approach (eq. 5) can be used. 
For evaluation and comparison of the experimental and modeled data the conversion $X$ of ethylene, propylene and carbon monoxide (eq. 10) and the yield $Y$ of carbon monoxide and carbon dioxide (eq. 11) are used.

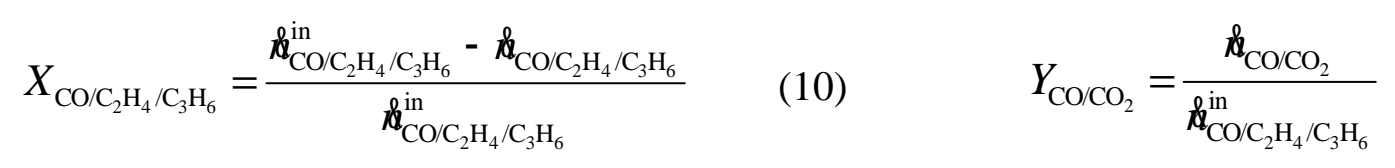

\section{Experimental equipment and procedures}

The kinetic experiments were carried out in a lab scale test facility that consist of a gas supply, a furnace with an integrated quartz glass reactor and a gas chromatograph analytic with a heated multi-position valve which enable a gas analysis of the reactants and products. The reactant feed gas composed of ethylene (Air Liquide 3.0), propylene (Westfalen Gas 2.5) or carbon monoxide (Linde 4.7) in mixtures of air (technical grade) and nitrogen (Air Liquide 5.0). Total inlet flow was set using mass flow controllers (Bronkhorst).

The tubular reactor (fused silica glass) with a length of $0.4 \mathrm{~m}$ and the inner diameter of $0.006 \mathrm{~m}$ was filled with $0.1827 \mathrm{~g}$ of the $\mathrm{CrO}_{\mathrm{x}} / \gamma-\mathrm{Al}_{2} \mathrm{O}_{3}$ powdered catalyst particles $\left(d_{\mathrm{p}}=150-250 \mu \mathrm{m}\right)$ to avoid mass transport limitations proven in preliminary experiments. The catalyst bed is encased with inert particles $\left(\mathrm{ZrO}_{2} / \mathrm{SiO}_{2}, d_{\mathrm{p}}=0.001-0.00125 \mathrm{~m}\right.$, Mühlmeier), which is used as a preheating zone of the feed gas and to achieve an ideal mixture of the components in the gas phase. The reactor is embedded in a furnace (HTM Reetz). Thus, the temperature can be set between $25-1000{ }^{\circ} \mathrm{C}$. The temperature is controlled by a thermo sensing element which is placed in the center of the catalyst bed. Addition a thermo sensing element is positioned at the beginning and the end of the catalyst bed, respectively.

The quantitative analysis of the gas composition was carried out with an online GC-TCD/MSD (Agilent GC 6890) system equipped with a two column configuration. In the first column (HP Plot Q) the hydrocarbons and carbon dioxide are separated. The second column (HP Molsieve) separates the permanent gases and carbon monoxide.

The kinetic experiments were performed at a total volume flux $\left(215 \mathrm{ml} / \mathrm{min}, \mathrm{STP} 25^{\circ} \mathrm{C}\right)$ corresponding to a catalyst weight to volume flux ratio $W / F$ of $50(\mathrm{~kg} \cdot \mathrm{s}) / \mathrm{m}^{3}$. The pressure drop of all kinetic experiments over the reactor length was less than $0.02 \mathrm{MPa}$ and used as boundary conditions in the Ergun-equation (eq. 8) in the kinetic modeling. The kinetic experiments were 
done as function of the temperature $\left(T=300-650{ }^{\circ} \mathrm{C}\right)$ and of the ethylene $\left(x_{\mathrm{C} 2 \mathrm{H} 4}=0-1 \%\right)$, propylene $\left(x_{\mathrm{C} 3 \mathrm{H} 6}=0-1 \%\right)$, carbon monoxide $\left(x_{\mathrm{CO}}=0-1 \%\right)$ and oxygen $\left(x_{\mathrm{O} 2}=0-20.9 \%\right)$ concentration. Each set of inlet concentration conditions and reaction temperatures was held for at least $0.5 \mathrm{~h}$ to obtain two gas samples at steady state conditions. Thus, the observed experimental data corresponds to average values of at least two independent measurements.

To evaluate the experimental data, the carbon balance was analyzed for each data point. The error is $\pm 5 \%$ and therefore within the exactness of the used analytic GC measurement. Thus, additional side reactions or components cannot be observed. Furthermore, the catalyst activity regarding the oxidation reactions was found as constant in regularly time intervals.

The experimental program performed for the three different sub-networks and the complex total reaction network consist of

a) Sub-network I: 360 steady state conditions at 20 different temperatures, 4 different inlet carbon monoxide concentrations and 7 different inlet oxygen concentrations

b) Sub-network II: 360 steady state conditions at 20 different temperatures, 4 different inlet ethylene concentrations and 7 different inlet oxygen concentrations

c) Sub-network III: 160 steady state conditions at 20 different temperatures, 4 different inlet propylene concentrations and 7 different inlet oxygen concentrations

d) Total network: 120 steady state conditions at 5 different ethylene to propylene mixtures at one inlet oxygen concentration

\section{Preliminary adsorption measurements}

As aforementioned as a model reduction technique [32] the adsorption equilibrium parameters of the reactants and products (see eqs. 3 and 4) on the $\mathrm{CrO}_{\mathrm{x}} / \gamma-\mathrm{Al}_{2} \mathrm{O}_{3}$ catalyst were investigated in previous work [45] separately. Therefore, single component adsorption measurements covering the whole reaction temperature region were done. On the basis of these experimental data the adsorption parameters were estimated by means of a Langmuir adsorption isotherm model (eq. 12). The temperature dependence of the adsorption parameters were given with an Arrhenius equation (eq. 5). The corresponding estimated parameters can be seen in tab. 1 .

$$
q_{j_{\mathrm{c}}}=q_{j_{\mathrm{c}}}^{\text {sat }} \frac{(K p)_{j_{\mathrm{c}}}}{1+(K p)_{j_{\mathrm{c}}}}
$$


Based on this equation the single component adsorption equilibrium constant $K_{j \mathrm{c}}$ can be directly transferred to the LH (eq. 4) and ER (eq. 3) reaction rate approaches without any reparameterization.

\section{Results and discussion}

\subsection{Carbon monoxide oxidation: sub-network I}

For the reaction kinetic analysis of the total oxidation of carbon monoxide three different rate approaches (eqs. 2-4) were determined and quantified as discussed in section 3. To avoid parameter correlation and for improving the comparability of the rate approaches the adsorption constants of the ER and LH mechanism were already estimated independently from the occurring reaction [45]. As presented the competitive adsorption behavior can be described via Multi-Langmuir adsorption isotherms. Thus, the adsorption parameters from tab. 1 are used without any modification in kinetic analysis. Based on the diluted system $\left(x_{\mathrm{CO}} \leq 1 \%\right)$ and the mean exothermal heat energy $\left(\Delta H_{\mathrm{R}}\left(T=500^{\circ} \mathrm{C}\right)=-283 \mathrm{~kJ} / \mathrm{mol}\right.$ [63] $)$ of the $\mathrm{CO}$ oxidation the kinetic experiments can be considered as isothermal.

To obtain a reliable kinetic equation the temperature dependence of the reaction rates was determined for four different carbon monoxide $\left(x_{\mathrm{CO}}=0.25-1.00 \%\right)$ and five oxygen $\left(x_{\mathrm{O} 2}=\right.$ 1.00-20.90\%) inlet molar ratios. The temperature is varied between $300-650{ }^{\circ} \mathrm{C}$. The comparison of experimental and modeled data concerning the three approaches is given in fig. 3a-b. Several measured reaction temperatures are illustrated at the molar inlet ratios of carbon monoxide and oxygen of $1.0 \%$ and $20.9 \%$, respectively. The catalyst weight to total volume flux ratio is $50 \mathrm{~kg}_{\text {cat }} \cdot \mathrm{s} / \mathrm{m}^{3}$. It is obvious that with increasing reaction temperature the conversion of carbon monoxide increases. The performance of the catalyst presents at $300{ }^{\circ} \mathrm{C}$ a conversion of $\mathrm{CO}$ close to zero. Above $450{ }^{\circ} \mathrm{C}$ the conversion is clearly emerging. Complete conversion of $\mathrm{CO}$ is reached at $625^{\circ} \mathrm{C}$ on the experiment setup selected.

During the adsorption based reaction mechanisms the shown experimental conversion and carbon dioxide yield data are overestimated. The reduced MvK approach (eq. 2) reflects the data in an excellent way (see fig. 3a-b). In this connection the estimated kinetic parameter are shown in tab. 2. It is apparently, that the activation energies of the approaches differ strongly from 97.5 $\mathrm{kJ} / \mathrm{mol}(\mathrm{MvK})$ up to $169 \mathrm{~kJ} / \mathrm{mol}(\mathrm{LH})$. This is reflected in fig. 3a-b, too. The gradients of the 
adsorbed based rate approaches are too stiff. However, the difficulty is not the temperature depends. Rather the dependency of the reaction rate on the reactant components cannot be described by the ER and LH model. In contrast the activation energy of the MvK approach is close to literature data. Liu [64] presented an activation energy of $91 \mathrm{~kJ} / \mathrm{mol}$ on a $\mathrm{CuO}-\mathrm{Cr}_{2} \mathrm{O}_{3} / \gamma$ $\mathrm{Al}_{2} \mathrm{O}_{3}$ catalyst for a semi-empirical ER approach. Thus, the carbon monoxide oxidation at a chromium based catalyst can be described by a MvK mechanism [22].

In order to illustrate the good prediction by $\mathrm{MvK}$ the comparison of the experimental performance parameter and the modeled data is shown in fig. $4 \mathrm{a}-\mathrm{d}$ for a wide carbon monoxide and oxygen inlet concentration range. Fig. 4a-b and c-d reveal the individual effect of carbon monoxide and oxygen at otherwise constant condition, respectively. It seems that the partial pressure effect of both components is poorly developed in the range considered. Only the temperature dependence can be observed. If the experimental stoichiometric ratio of carbon monoxide and oxygen is considered it becomes apparent that oxygen is in excess for all conditions. According to this the re-oxidation step of the catalyst species of the MvK mechanism (see fig. 2) seems to be not rate determining. Thus, in parameter quantification the activation energy of the oxidation step was estimated to be zero (see tab. 2).

In fig. 5a-b the influence of the catalyst weight to total volume flux ratio is shown. The description of this effect is not part of the kinetic rate equation but rather of the reactor model. This was already introduced in section 4. Accordingly, the experimental measured CO conversion and $\mathrm{CO}_{2}$ yield with a $W / F$ ratio of 100,150 and $200 \mathrm{~kg}_{\text {cat }} \mathrm{s}^{\mathrm{s}} / \mathrm{m}^{3}$ were predicted very well by the reactor model. If the $W / F$ ratio increases, the total volume flux decreases and hence the residence time increases. Consequential the $\mathrm{CO}$ conversion and $\mathrm{CO}_{2}$ yield increases at further constant conditions.

In the next steps of the more complex reaction network (II and III) analysis the already estimated kinetic parameter of reaction 5 (see fig. 1 and tab. 2) will be fixed. Thus, finally all parts and the total network can be described by the quantified kinetic approaches.

\subsection{Ethylene oxidation: sub-network II}

In the second sub-network the total $\left(r_{1}\right)$ and partial $\left(r_{2}\right)$ oxidation of ethylene were quantified. The experimental observation of the ethylene oxidation present for the selected inlet conditions $\left(x_{\mathrm{C} 2 \mathrm{H} 4}=1 \% ; x_{\mathrm{O} 2}=20.9 \%\right)$ that the ethylene conversion (fig. 6a) increases between $300{ }^{\circ} \mathrm{C}$ from 
close to zero to $550{ }^{\circ} \mathrm{C}$ up to $100 \%$. The resulting products are carbon monoxide and carbon dioxide. Further components were not observed by the used GC equipment. The experimental carbon monoxide yield (fig. 6b) increases between $300{ }^{\circ} \mathrm{C}$ and $500{ }^{\circ} \mathrm{C}$ from zero to maximum 50 $\%$. A further increase in temperature, supports the total oxidation of CO (see also sub-network I; section 7.1) thus the yield decreases to the point of zero at $650{ }^{\circ} \mathrm{C}$. The experimental yield of carbon dioxide (fig. 6c) increases continuously from zero to $100 \%$ in the chosen temperature range.

The kinetic parameter estimation procedure by network decomposition of ethylene and propylene oxidation in the sub-networks for the adsorbed based approaches is limited by the equilibrium adsorption constant of water. Due to not suitable equipment these individual adsorption measurements and the corresponding parameter estimation are missing in [45]. In literature the gaseous water adsorption at transition metal oxides is described as strongly pronounced $[3,11,55,65]$. Accordingly, the inhibition effect by water adsorption on the active catalyst species in resting state is apparent for all reaction rates in an analogous manner. Based on this, the parameter estimation of the remaining sub-networks followed simultaneously on the experimental data.

In previous articles several kinetic rate approaches were investigated to describe the total oxidation of short-chain olefins and alkanes. Starting with empirical [20, 65, 66] and semiempirical rate laws [55, 65] up to $\operatorname{ER}[64,65]$, $\operatorname{LH}[3,67]$ and $\operatorname{MvK}[66,68]$ approaches. Dependent on the active catalyst species and the reactant different approaches were suitable. In recently published articles spectroscopic techniques were used to identify active catalyst sites and analyze oxidation mechanisms reliable on a cupper-cerium oxide catalyst $[69,70]$ and $\mathrm{CrO}_{\mathrm{x}}$ catalyst [49].

In this work, the applied reaction rate models are the MvK (eq. 2), the ER (eq. 3) and the LH (eq. 4) mechanism as discussed before. The partial and total oxidation reactions of each reactant were described by the same mechanism. Based on parameter correlations for estimating the temperature depending on the reaction and adsorption behavior of water, the adsorption equilibrium parameter was estimated independently from temperature. The re-oxidation step of the catalyst species by gaseous oxygen for a MvK mechanism is independent of the catalyst reduction step. Accordingly, the reaction cycle step constant $k_{\mathrm{ox}}{ }^{+}$of the $\mathrm{CO}$ oxidation can be transferred to the ethylene and propylene oxidation, respectively. The estimated kinetic 
parameters of the several reaction rate approaches of sub-network II are listed in tab. 2. A comparison of the modeled temperature dependence for the performance parameters of the different reaction rate approaches are shown in fig. 6a-c. Additionally the experimentally measured data are presented in the figure, too.

The suitability of the derived rate approaches is pronounced differently. The trend of the performance parameters as a function of temperature is reflected by all models. Nevertheless the activation energies of the LH approaches are obviously greater than the rest of the studied mechanisms (see tab. 2). Thus, the corresponding ethylene conversion is under and overestimated at low and high temperatures by LH, respectively. Additionally, the yields of CO and $\mathrm{CO}_{2}$ possess major deviations. This is reflected by the MvK approach, too. Especially the yield of CO is widely underestimated. The most suitable approach for the description of the ethylene oxidation is the ER mechanism. Accordingly, gas phase ethylene reacts directly with the adsorbed oxygen catalyst species complex. Such characteristics of transition metal oxide catalysts for the total oxidation of short-chain alkanes and olefins have been observed by [55, 71, 72]. The comparison of the estimated activation energy of the total oxidation with literature data offers some deviations. Yao observed a value of $90 \mathrm{~kJ} / \mathrm{mol}$ for the ethylene oxidation on a commercialized $\mathrm{Cr}_{2} \mathrm{O}_{3}$ catalyst [20].

In order to clarify the suitability in fig. 7a-f the temperature dependence of the performance parameters is shown in a wide ethylene and oxygen concentration range. First the ethylene partial pressure dependence is investigated (see fig. 7a-c). For this purpose the ethylene molar inlet feed ratio is varied between $0.25-1.00$ percent. Further inlet conditions were set constant $\left(x_{\mathrm{O} 2}=20.9 \% ; W / F=50 \mathrm{~kg}_{\text {cat }} \cdot \mathrm{s} / \mathrm{m}^{3}\right)$. With increasing ethylene concentration the conversion slightly decreases at a constant reaction temperature. Accordingly, the yield of $\mathrm{CO}$ and $\mathrm{CO}_{2}$ decreases marginal, too. This is related to the needed higher residence time of a larger quantity of ethylene. The effect of increasing released heat of reaction with increased in the ethylene concentration can only be notified above $450{ }^{\circ} \mathrm{C}$ and is considered in the kinetic modeling as well.

Second the effect of the oxygen inlet concentration is studied in fig. 7d-f at a constant ethylene molar inlet ratio $\left(x_{\mathrm{C} 2 \mathrm{H} 4}=1.0 \%\right)$. Based on oxygen excess conditions the concentration decreases to the point of oxygen deficiency. The first decrease in oxygen affects the performance parameter marginally. Only below stoichiometric conditions the influence is obvious. It is clear 
that the oxygen concentration limits the ethylene conversion (fig. 7d). As a result the yield of CO increases (fig. 7e) and the yield of $\mathrm{CO}_{2}$ (fig. 7f) decreases strongly at high reaction temperatures, respectively. This behavior is reflected by the ER kinetic model as well.

Also in the ethylene sub-network the effect of the residence time is studied individually (see fig. $8 \mathrm{a}-\mathrm{c})$. As aforementioned this is part of the reactor model and cannot be reflected by the reaction kinetic. The investigation was performed by constant inlet molar ratios $\left(x_{\mathrm{O} 2}=20.9 \% ; x_{\mathrm{C} 2 \mathrm{H} 4}=\right.$ $1.0 \%$ ). The catalyst weight to total volume flux ratio is varied between 50 and $150 \mathrm{~kg}_{\text {cat }} \cdot \mathrm{s} / \mathrm{m}^{3}$. Expectedly, with an increase in residence time the conversion of ethylene increases. This results in higher $\mathrm{CO}$ and $\mathrm{CO}_{2}$ yields at constant reaction temperatures, respectively. Generally, the reduced reactor model reflects the experimental data well. Nevertheless the yield of $\mathrm{CO}$ is underestimated and $\mathrm{CO}_{2}$ overestimated at low and high temperatures, respectively. But the trend is obviously.

\subsection{Propylene oxidation: sub-network III}

The sub-network III contains the total $\left(r_{3}\right)$ and partial $\left(r_{4}\right)$ oxidation reaction of propylene as well as the previously estimated oxidation of $\mathrm{CO}\left(r_{5}\right)$. The quantification of the reaction rates was performed in an analogous manner to the ethylene sub-network II. The needed adsorption equilibrium constant of water $\left(K_{\mathrm{H} 2 \mathrm{O}}\right)$ for the adsorption based reaction rate approaches was already introduced in section 7.2. The re-oxidation constant $\left(k_{\mathrm{ox}}{ }^{+}\right)$of the MvK approach was already estimated in sub-network I. The comparison of the quantified rate models and the corresponding experimental data of one inlet feed composition $\left(x_{\mathrm{C} 3 \mathrm{H} 6}=0.5 \% ; x_{\mathrm{O} 2}=20.9 \%\right.$; $W / F=50 \mathrm{~kg}_{\mathrm{cat}} \cdot \mathrm{s} / \mathrm{m}^{3}$ ) is shown in fig. 9a-c. The associated kinetic parameters und their $95 \%$ confidence intervals of several rate approaches are given in tab. 2.

The experimentally observed performance parameters and dependencies on reaction temperature and reactant concentrations are analog to the ethylene oxidation. Based on the chain length of propylene the oxidation reactivity is increased compared to ethylene [20]. Additionally, the total oxidation enthalpy of reaction is clearly increased, too. Calculated values of reaction $r_{1}$ and $r_{3}$ are $\Delta H_{\mathrm{R}, 1}\left(T=500^{\circ} \mathrm{C}\right)=-1322 \mathrm{~kJ} / \mathrm{mol}$ and $\Delta H_{\mathrm{R}, 3}\left(T=500^{\circ} \mathrm{C}\right)=-1925 \mathrm{~kJ} / \mathrm{mol}$, respectively (see fig. 1) [63]. Accordingly, the temperature control process across along the catalyst bed is more complicated. The maximum observed temperature range was amounted to $80{ }^{\circ} \mathrm{C}$ at $8 \mathrm{~mm}$ 
catalyst bed length. Based on this reason, the experimental data of the propylene oxidation were restricted to either small propylene or oxygen concentration, respectively.

The comparison of the estimated rate approaches present that the ER and LH mechanism reflect the experimental example data well (see fig. 9a-c). The predicted values of the LH approach are in good agreement with the yield of $\mathrm{CO}$ and $\mathrm{CO}_{2}$. However, the observed boundary range offers large deviation. The performance of the MvK mechanism faded compared to the others. Accordingly, the ER approach is used to describe the whole experimental data set of the propylene total and partial oxidation. Compared to literature data the activation energy of the total oxidation of propylene is estimated in a similar dimension. Zahn [57] reported a value of $128.4 \pm 17.2 \mathrm{~kJ} / \mathrm{mol}$ for an empiric power law approach on a $\mathrm{Cu}-\mathrm{CrO}_{\mathrm{x}} / \gamma-\mathrm{Al}_{2} \mathrm{O}_{3}$ catalyst and Yao [20] $101 \mathrm{~kJ} / \mathrm{mol}$ on a $\mathrm{Cr}_{2} \mathrm{O}_{3}$ catalyst, respectively.

In fig. 10a-f a comparison of experimental and modeled performance parameter for a broad propylene and oxygen concentration range is shown. At a constant oxygen inlet molar fraction $\left(x_{\mathrm{O} 2}=1.0 \%\right)$ the propylene feed concentration is varied between $x_{\mathrm{C} 3 \mathrm{H} 6}=0.25-1.0 \%$ (see fig. $10 \mathrm{a}-\mathrm{c})$. With an increase of the propylene partial pressure the steady state conversion decreases at constant residence time conditions $\left(W / F=50 \mathrm{~kg}_{\mathrm{cat}} \cdot \mathrm{s} / \mathrm{m}^{3}\right)$. In parallel the yield of $\mathrm{CO}$ and $\mathrm{CO}_{2}$ decreases, too. In kinetic modeling the effect can be reflected as well. Nevertheless, the yield of $\mathrm{CO}$ and $\mathrm{CO}_{2}$ is strongly under and overestimated for the minimal propylene concentration studied, respectively.

The effect of the oxygen concentration (see fig. 10d-f) is only visible below stoichiometric conditions. This is obviously at the limited propylene conversion. The corresponding yield of CO and $\mathrm{CO}_{2}$ is affected by the oxygen limitation, too. However, at this point the kinetic modeling cannot reflect the experimental data. At oxygen excess conditions the performance parameters are only slightly affected. With an increase in oxygen concentration the propylene conversion increases, too. The corresponding yield of $\mathrm{CO}$ and $\mathrm{CO}_{2}$ first increases equivalent. At higher reaction temperatures the following total oxidation of $\mathrm{CO}\left(r_{5}\right)$ is also supported. This leads to a strong decrease of the $\mathrm{CO}$ yield.

The investigation of the residence time effect on the sub-network III is performed at $x_{\mathrm{C} 3 \mathrm{H} 6}=$ $0.5 \%$ and $x_{\mathrm{O} 2}=20.9 \%$ as inlet composition. Based on the experimental plant limitation the catalyst weight to total volume flux ratio is varied between 50 and $100 \mathrm{~kg}$ cat $\cdot \mathrm{s} / \mathrm{m}^{3}$. The comparison of the experimental and modeled performance parameter is shown in fig. 11a-c. As 
aforementioned in sub-network I and II, respectively, with increase in residence time the conversion of propylene increases, too. The modeled effect is much more pronounced as experimentally validated. This can be observed for the yield of $\mathrm{CO}$ and $\mathrm{CO}_{2}$, too.

\subsection{Evaluation of the total oxidation reaction network}

In the previous analysis of the three sub-networks all reaction kinetic parameters have been estimated (see bold parameters in tab. 2). Thus, in the following chapter the reaction kinetic will be validated at mixture conditions which are not considered at parameter estimation. Therefore, no additional parameter estimation will be done. The validation occurred at oxygen excess $\left(x_{\mathrm{O} 2}=\right.$ $20.9 \%$ ) and a catalyst weight to total volume flux ratio of $50 \mathrm{~kg}_{\mathrm{cat}} \cdot \mathrm{s} / \mathrm{m}^{3}$. Often inhibition effects based on competitive adsorption of the reactants are reported in literature $[57,73]$. To analyze the mutual retardation of the hydrocarbon oxidation in mixtures first the ethylene inlet concentration is set constant and the propylene molar ratio is varied between 0 and $0.75 \%$. The experimental and modeled performance parameters are shown in fig. 12a-d. The opposite variation $\left(x_{\mathrm{C} 3 \mathrm{H} 6}=\right.$ const. $=0.25 \%$ and ethylene molar ratio is varied between 0 and $\left.0.75 \%\right)$ is illustrated in fig. 13a-d. It is obvious that mutual retardation occurred for both cases. Only the magnitude is differently pronounced. The conversion of the reactants for several conditions reveals that the ethylene oxidation is strongly inhibited by propylene addition. Vice versa only a marginal effect can be observed. This was already determined at the competitive adsorption measurements of ethylene and propylene [45]. In this connection the Multi-Langmuir adsorption model reflect the competitive adsorption behavior for the active catalyst sites well [45]. By including the individual estimated single component adsorption parameter in the ER kinetic approach the effect and also the order of the magnitude can be reflected by the kinetic model as well (see figs. 12 and 13). This reaction order and the corresponding inhibition effects of the hydrocarbon oxidation is already observed by several transition metal oxide catalysts [20, 74]. For the yield of $\mathrm{CO}$ and $\mathrm{CO}_{2}$ the effect of the competitive component adsorption can be studied in detail. Whereas the yield of $\mathrm{CO}$ and according to this the partial oxidation reactions $\left(r_{2}\right.$ and $\left.r_{4}\right)$ are only slightly effected. The yield of $\mathrm{CO}_{2}$ increases significantly with an increase of the competitive component at lower reaction temperatures. 


\section{Conclusion}

In this contribution the partial and total oxidation of ethylene and propylene separately and in mixtures on a $\mathrm{CrO}_{\mathrm{x}} / \gamma-\mathrm{Al}_{2} \mathrm{O}_{3}$ catalyst were investigated in a broad range of temperature and reactant concentration, respectively. According to $\mathrm{Hu}$ et al. and Kiedorf et al. [25, 53] the complex total reaction network was decomposed in three sub-networks with ascending complexity to support estimating free kinetic parameters in rate equations for identified reactions. Several detailed kinetic mechanistic rate equations were derived based on oxidationreduction and adsorption-desorption reaction mechanisms postulated in a general catalytic cycle. To reduce the quantity of kinetic rate parameters and avoid linear dependencies at parameter estimation the adsorption equilibrium constants of each component were studied separately without reaction. Therefore, single component adsorption isotherms for all reactants and products, except water, were measured in a broad temperature and concentration range. A combination of Henry and Langmuir model was adapted at the experimental data. Additionally, as reference a general Langmuir adsorption model was estimated. Competitive adsorption isotherms were predicted using the Ideal Adsorbed Solution Theory and the Multi-Langmuir model. Using the Multi-Langmuir adsorption model parameter, only the kinetic constants of the adsorbed based rate approaches were quantified and evaluated at kinetic experimental data for each sub- and the total network, respectively. The rate approaches with the best experimental data agreement including estimated parameters were transferred in the next sub-network. According to this the carbon monoxide oxidation corresponds to the MvK mechanism [22] and the ethylene and propylene partial and total oxidation reactions to the ER mechanism [20]. For evaluation of the reaction pathway this method has only limited suitability [24]. The reactant oxidation occurs with gas phase, adsorbed and lattice oxygen on the $\mathrm{CrO}_{\mathrm{x}} / \gamma-\mathrm{Al}_{2} \mathrm{O}_{3}$ catalyst, respectively. But only the dominate reaction pathway will be described by the reaction kinetic. However, the validated rate approaches reflect the experimental data on the whole observed temperature and concentration range very well. For this purpose the conversion parity plots of several sub-networks are shown in fig. 14. Only the propylene conversion (sub-network III) possesses a systematic deviation at lower and higher reaction temperatures, respectively. This can be also by difficult experimental properties because of the high values for released heat of reaction. 
The estimated activation energy of the ethylene total oxidation reaction $\left(E_{\mathrm{A}, 1}=57 \mathrm{~kJ} / \mathrm{mol}\right)$ is obviously smaller as of the partial oxidation reaction $\left(E_{\mathrm{A}, 2}=111 \mathrm{~kJ} / \mathrm{mol}\right)$. The identical trend can be observed for the propylene oxidation $\left(E_{\mathrm{A}, 3}=86 \mathrm{~kJ} / \mathrm{mol}\right.$ and $\left.E_{\mathrm{A}, 4}=102 \mathrm{~kJ} / \mathrm{mol}\right)$. For the comparison of the ethylene and propylene oxidation no distinct trend can be observed. The activation energy of the total oxidation increases with the increase in the chain length and for the partial oxidation the opposite occurs. The activation energy of the carbon monoxide oxidation is $97 \mathrm{~kJ} / \mathrm{mol}$, which is close to literature data [64]. The calculated $95 \%$ confidence intervals of the estimated parameters are mostly in a significant range. Especially the confidence intervals of the activation energies are less than $11 \%$.

Based on the estimated reaction kinetic new innovative integrated reactor concepts can be used in reactor development and process optimization and control.

\section{Acknowledgements}

This work is part of the Collaborative Research Center/ Transregio 63 "Integrated Chemical Processes in Liquid Multiphase Systems" (subproject A3). Financial support by the Deutsche Forschungsgemeinschaft (DFG, German Research Foundation) is gratefully acknowledged (TRR 63).

\section{Nomenclature}

\section{Latin letters}

\begin{tabular}{|c|c|c|}
\hline$d$ & $\mathrm{~m}$ & diameter \\
\hline$E_{\mathrm{A}}$ & $\mathrm{kJ} / \mathrm{mol}$ & activation energy \\
\hline$\Delta H_{\mathrm{ads}}$ & $\mathrm{kJ} / \mathrm{mol}$ & sorption enthalpy \\
\hline$\Delta H_{\mathrm{R}}$ & $\mathrm{kJ} / \mathrm{mol}$ & enthalpy of reaction \\
\hline$K$ & $\mathrm{~Pa}$ & adsorption constant \\
\hline$j$ & - & index \\
\hline$k$ & varies & reaction rate constant \\
\hline$m$ & $\mathrm{~kg}$ & mass \\
\hline$\dot{n}$ & $\mathrm{~mol} / \mathrm{s}$ & molar flux \\
\hline$O F$ & - & objective function \\
\hline$p$ & $\mathrm{~Pa}$ & pressure \\
\hline$q$ & $\mathrm{~mol} / \mathrm{kg}_{\text {cat }}$ & load capacity \\
\hline$R$ & $\mathrm{~J} /(\mathrm{mol} \cdot \mathrm{K})$ & universal gas constant \\
\hline$r$ & $\mathrm{~mol} /\left(\mathrm{kg}_{\text {cat }} \cdot \mathrm{s}\right)$ & reaction rate \\
\hline$T$ & $\mathrm{~K}$ or ${ }^{\circ} \mathrm{C}$ & temperature \\
\hline$u$ & $\mathrm{~m} / \mathrm{s}$ & velocity \\
\hline
\end{tabular}




$\begin{array}{lll}V & \mathrm{~m}^{3} & \text { volume } \\ \dot{V} & \mathrm{~m}^{3} / \mathrm{s} & \text { volume flux } \\ W / F & \left(\mathrm{~kg}_{\text {cat }} \cdot \mathrm{s}\right) / \mathrm{m}^{3} & \text { catalyst weight to volume flux ratio } \\ X & \% & \text { conversion } \\ x & \% & \text { molar ratio } \\ Y & \% & \text { yield } \\ y_{\text {obs }} & - & \text { observed system response } \\ \mathrm{Z} & \mathrm{m} & \text { spatial coordinate }\end{array}$

\section{Greek letters}

$\begin{array}{lll}\varepsilon & - & \text { void fraction } \\ \eta & \mathrm{Pa} \cdot \mathrm{s} & \text { dynamic viscosity } \\ \Theta_{\mathrm{opt}} & - & \text { optimization parameter vector } \\ \rho & \mathrm{kg} / \mathrm{m}^{3} & \text { density } \\ \omega & - & \text { reaction step frequency }\end{array}$

\section{Subscripts}

$\begin{array}{ll}\text { c } & \text { component } \\ \text { cat } & \text { catalyst } \\ \text { exp } & \text { experimental } \\ \text { mod } & \text { modeled } \\ \text { ox } & \text { oxidation } \\ \mathrm{P} & \text { particle } \\ \mathrm{R} & \text { reaction } \\ \text { red } & \text { reduction } \\ \text { sat } & \text { saturation } \\ \text { tot } & \text { total }\end{array}$

\section{Superscripts}

$N_{\mathrm{c}}$

$N_{\text {obs }}$

$N_{\mathrm{R}}$

\section{Abbreviation}

CI

ER

confidence interval

Eley-Rideal

LH

$\mathrm{MvK}$ number of components

number of observations

number of reactions
Langmuir-Hinshelwood

Mars-van Krevelen 


\section{Appendix}

At kinetic parameter estimation problems the additional solving of a thermal energy balance is quite difficult because of parameter correlation [24]. Therefore, the use of an empirical polynomial approach is suitable (see eq. A1).

$$
T(z)=P_{\mathrm{T}, 1} z^{2}+P_{\mathrm{T}, 2} z+P_{\mathrm{T}, 3}
$$

By means of eq. A1 predictions of temperature profiles are not possible. Accordingly, experimental temperature data are needed to estimate $P_{\mathrm{T}, 1-3}$ separately.

\section{References}

[1] J. J. Spivey, Ind. Eng. Chem. Res. 1987, 26 (11), 2165.

[2] G. J. Hutchings, S. H. Taylor, Catalysis Today 1999, 49 (1-3), 105.

[3] M. P. Heynderickx et al., Applied Catalysis B: Environmental 2010, 95 (1-2), 26.

[4] J. J. Spivey, J. B. Butt, Catalysis Today 1992, 11 (4), 465.

[5] N. Burgos, M. Paulis, M. Mirari Antxustegi, M. Montes, Applied Catalysis B: Environmental 2002, 38 (4), 251.

[6] S. E. Voltz, C. R. Morgan, D. Liederman, S. M. Jacob, Ind. Eng. Chem. Prod. Res. Dev. 1973, 12 (4), 294.

[7] R. K. Herz, S. P. Marin, Journal of Catalysis 1980, 65 (2), 281.

[8] D. J. Hautman, F. L. Dryer, K. P. Schug, I. Glassman, Combustion Science and Technology 1981, 25 (5-6), 219.

[9] A. Baylet et al., Applied Catalysis B: Environmental 2011, 102 (1-2), 180.

[10] T. Choudhary, S. Banerjee, V. Choudhary, Applied Catalysis A: General 2002, 234 (1-2), 1.

[11] P. Hurtado, S. Ordóñez, H. Sastre, F. V. Díez, Applied Catalysis B: Environmental 2004, 51 (4), 229.

[12] R. H. Nibbelke, A. J. Nievergeld, J. H. Hoebink, G. B. Marin, Applied Catalysis B: Environmental 1998, 19 (3-4), 245.

[13] Harmsen, Jan M. A., Hoebink, Jozef H. B. J., J. C. Schouten, Ind. Eng. Chem. Res. 2000, 39 (3), 599.

[14] Q. Liu et al., Journal of Catalysis 2009, 263 (1), 104.

[15] D. M. Gómez et al., Physical chemistry chemical physics PCCP 2014, 16 (23), 11447.

[16] S. Wang et al., Applied Catalysis A: General 2000, 196 (1), 1.

[17] M. Panizza et al., Chemical Engineering Journal 2003, 93 (3), 181.

[18] I. Nova et al., AIChE J. 2009, 55 (6), 1514.

[19] M. Bettahar, G. Costentin, L. Savary, J. Lavalley, Applied Catalysis A: General 1996, 145 (1-2), 1.

[20] Y.-F. Y. Yao, Journal of Catalysis 1973, 28 (1), 139.

[21] P. Mars, D. W. van Krevelen, Special Supplement to Chemical Engineering Science 1954, 3, 41.

[22] D. Murzin, T. Salmi, Catalytic Kinetics, Elsevier, Amsterdam 2005.

[23] F. Klose, M. Joshi, C. Hamel, A. Seidel-Morgenstern, Applied Catalysis A: General 2004, 260 (1), 101. 
[24] F. G. Helfferich, Kinetics of multistep reactions, 2nd ed., Comprehensive chemical kinetics, v. 40, Elsevier, Amsterdam, Boston 2004.

[25] G. Kiedorf et al., Chemical Engineering Science 2014, 115, 31.

[26] P. H. K. Kripylo, D. Klose, T. Khuat Minh, Chemische Technik (Leipzig) 1984, 36 (2), 58.

[27] H. Redlingshöfer et al., Ind. Eng. Chem. Res. 2003, 42 (22), 5482.

[28] J. L. Ayastuy, A. Gurbani, M. P. González-Marcos, M. A. Gutiérrez-Ortiz, Ind. Eng. Chem. Res. 2009, 48 (12), 5633.

[29] K. Toch, J. W. Thybaut, G. B. Marin, AIChE J. 2015, 61 (3), 880.

[30] M. J. Insausti, F. Mata-Perez, M. P. Alvarez-Macho, Int. J. Chem. Kinet. 1991, 23 (7), 593.

[31] J. F. Denayer et al., Applied Catalysis A: General 2003, 246 (1), 17.

[32] T. Pöpken, L. Götze, J. Gmehling, Ind. Eng. Chem. Res. 2000, 39 (7), 2601.

[33] G. H. Golub, C. F. van Loan, Matrix computations, 3rd ed., Johns Hopkins studies in the mathematical sciences, Johns Hopkins University Press, Baltimore 1996.

[34] M. Burth, G. C. Verghese, M. Velez-Reyes, IEEE Trans. Power Syst. 1999, 14 (1), 218.

[35] M. Fink, A. Attarian, H. Tran, Proc. Appl. Math. Mech. 2007, 7 (1), 1121501.

[36] T. Barz, López Cárdenas, Diana C., H. Arellano-Garcia, G. Wozny, AIChE J. 2013, 59 (6), 1981.

[37] A. Jörke, S. Triemer, A. Seidel-Morgenstern, C. Hamel, Chemie Ingenieur Technik 2015, 87 (6), 713.

[38] W. Yu, K. Hidajat, A. K. Ray, Applied Catalysis A: General 2004, 260 (2), 191.

[39] M. Schmitt, H. Hasse, Ind. Eng. Chem. Res. 2006, 45 (12), 4123.

[40] J. F. M. Denayer, G. V. Baron, Adsorption 1997, 3 (4), 251.

[41] A. Corma, F. Ortega, Journal of Catalysis 2005, 233 (2), 257.

[42] M. Al-Sabawi, H. de Lasa, AIChE J. 2009, 55 (6), 1538.

[43] D. Y. Murzin et al., Reaction Kinetics and Catalysis Letters 1997, 61 (2), 227.

[44] H. Thamm, H. Stach, W. Fiebig, Zeolites 1983, 3 (2), 95.

[45] G. Kiedorf, T. Wolff, A. Seidel-Morgenstern, C. Hamel, Chemical Engineering Science 2016, 149, 266.

[46] A. Seidel-Morgenstern, Journal of Chromatography A 2004, 1037 (1-2), 255.

[47] C. J. Radke, J. M. Prausnitz, AIChE J. 1972, 18 (4), 761.

[48] A. L. Myers, J. M. Prausnitz, AIChE J. 1965, 11 (1), 121.

[49] J. J. H. B. Sattler, J. Ruiz-Martinez, E. Santillan-Jimenez, B. M. Weckhuysen, Chemical reviews 2014, 114 (20), 10613.

[50] B. K. Hodnett, Heterogeneous catalytic oxidation: Fundamental and technological aspects of the selective and total oxidation of organic compounds, John Wiley, Chichester, New York 2000.

[51] P. S. Van Damme, S. Narayanan, G. F. Froment, AIChE J. 1975, 21 (6), 1065.

[52] M. P. Lobera, C. Téllez, J. Herguido, M. Menéndez, Applied Catalysis A: General 2008, 349 (1-2), 156.

[53] W. Hu, B. Lowry, A. Varma, Applied Catalysis B: Environmental 2011.

[54] M. Baerns, Technische Chemie, Wiley-VCH-Verl, Weinheim 2006.

[55] R. Auer, F. C. Thyrion, Ind. Eng. Chem. Res. 2002, 41 (4), 680.

[56] G. F. Froment, K. B. Bischoff, Chemical reactor analysis and design, 2nd ed., Wiley series in chemical engineering, Wiley, New York 1990. 
[57] V. M. Zahn, Adiabatic simulated moving bed reactor: Principle, nonlinear analysis and experimental demonstration, Forschungsberichte aus dem Max-Planck-Institut für Dynamik Komplexer Technischer Systeme, Bd. 37, Shaker, Aachen 2012.

[58] M. Giese, K. Rottschäfer, D. Vortmeyer, AIChE Journal 1998, 44 (2), 484.

[59] S. Ergun, Chem. Eng. Proc. 1952, 48 (2), 89.

[60] S. Ergun, A. A. Orning, Ind. Eng. Chem. 1949, 41 (6), 1179.

[61] M. Joshi, Statistical analysis of models and parameters in chemical and biochemical reaction networks, Logos-Verl, Berlin 2007.

[62] M. Schwaab, J. C. Pinto, Chemical Engineering Science 2007, 62 (10), 2750.

[63] C. L. Yaws, Chemical properties handbook: Physical, thermodynamic, environmental, transport, safety, and health related properties for organic and inorganic chemicals, McGraw-Hill handbooks, McGraw-Hill, New York 1999.

[64] W. Liu, M. Flytzanistephanopoulos, Journal of Catalysis 1995, 153 (2), 317.

[65] K. Sup Song, D. Klvana, J. Kirchnerova, Applied Catalysis A: General 2001, 213 (1), 113.

[66] J. Haber, W. Turek, Journal of Catalysis 2000, 190 (2), 320.

[67] S. Benard et al., Catalysis Communications 2013, 36, 63.

[68] P. M. Heynderickx et al., Journal of Catalysis 2010, 272 (1), 109.

[69] R. Zhang, J. T. Miller, C. D. Baertsch, Journal of Catalysis 2012, 294, 69.

[70] U. Menon et al., Journal of Catalysis 2012, 295, 91.

[71] T.-N. Angelidis, V. Tzitzios, in Reaction Kinetics and the Development of Catalytic Processes, Vol. 122 (Eds: G. F. Froment, K. C. Waugh), Elsevier 1999.

[72] J. W. Veldsink, G. F. Versteeg, W. van Swaaij, The Chemical Engineering Journal and the Biochemical Engineering Journal 1995, 57 (3), 273.

[73] J. J. Spivey, in Handbook of Heterogeneous Catalysis (Eds: G. Ertl, H. Knözinger, F. Schüth, J. Weitkamp), Wiley-VCH Verlag GmbH \& Co. KGaA. Weinheim, Germany 2008.

[74] Y. Moro-Oka, Y. Morikawa, A. Ozaki, Journal of Catalysis 1967, 7 (1), 23. 